\title{
STRESS-STRAIN CHARACTERISTICS OF WOOL AS RELATED TO ITS CHEMICAL CONSTITUTION
}

\author{
By Arnold M. Sookne and Milton Harris ${ }^{1}$
}

\section{ABSTRACT}

An apparatus for studying the extensibility of single wool fibers is described. Data on the effects of the tanning (quinone), dyeing, and deamination processes, and of neutral salts on the extensibility of wool fibers are reported. The results indicate that the extensibility of the wool fibers is governed, for the most part, by factors which influence the swelling or hydration of the protein. Salt linkages of the type which might be formed by an attraction between the free amino and carboxyl groups in wool do not appreciably contribute to the physical stability of the fiber in aqueous solutions.

\section{CONTENTS}

Page

I. Introduction

II. Description of apparatus and method

III. Results and discussion

1. Effect of tanning 539

2. Effect of dyeing with acid dyes

3. Effect of deamination $\ldots \ldots \ldots 42$

4. Effect of neutral salts 545

IV. Relation of swelling to the extensibility of wool

V. Summary

VI. References _... 549

\section{INTRODUCTION}

The classical view of protein structure, based on the work of Emil Fischer and his contemporaries, is that the protein molecule is a polypeptide composed of a series of amino acids united through their carboxyl and amino groups. These earlier workers focused their attention on the isolation and identification of the protein constituents and obtained large amounts of information which supported this view. Their work was of great importance in protein chemistry, but from the standpoint of protein structure, and more especially, the structure of protein fibers, it proved of limited value until recently, when it was augmented by physical-chemical methods and X-ray studies.

The more recent advances in the X-ray studies of wool and similar materials have been made by Astbury and his collaborators [1] ${ }^{2}$, whose investigations indicate that the fiber consists of long-chain molecules (polypeptides) which lie parallel to the fiber axis and which are held together by a variety of cross-linkages of the covalent and electrovalent types. That most of the covalent cross linkages in wool

1 Research Associates at the National Bureau of Standards, representing the American Association of Textile Chemists and Colorists. This work was aided by grants from the Textile Foundation, Inc., and the Chemical Foundation, Inc.

${ }_{2}$ Numbers in brackets indicate literature references at the end of this paper. 
are those of the disulfide groups of the amino acid, cystine, is at the present time generally accepted. On the other hand, little is known about the nature of the electrovalent forces.

As a result of a number of studies, principally on the changes in the extensibility of wool brought about by various treatments of the fiber, Speakman and Hirst [2] postulated the existence of electrovalent linkages between the free acid groups of the glutamic and aspartic acids and the free basic groups of the arginine, lysine, and histidine constituents of the polypeptides in wool, which they termed salt linkages. Presumably the attractive forces between the oppositely charged $\mathrm{R}-\mathrm{COO}_{-}^{-}$and $\mathrm{R}-\mathrm{NH}^{+}$ions are reduced by water and for this reason the wool fiber is more easily stretched in water than in dry air. Similarly, they postulated that since acids and alkalies would depress the ionization of the free acid and basic groups which make up the salt linkage, they would increase the ease of stretching to an even greater extent.

The presence of salt linkages in various proteins has been suggested by different investigators and there appears to be some evidence for their existence. The question has arisen therefore as to whether salt linkages, formed by the attraction between the free amino and carboxyl groups, contribute appreciably to the physical strength of the wool fibers.

The results of studies on the extensibility of wool fibers are reported here for the purpose of further elucidating the nature of the electrovalent linkages in wool. In addition, some of the data have been applied to an interpretation of the tanning, dyeing, and deamination of wool.

\section{DESCRIPTION OF APPARATUS AND METHOD}

The stretching of wool under load has been extensively investigated by Harrison [3], Karger and Schmid [4], Shorter [5], Astbury and Woods $[6]$ and especially by Speakman $[2,7]$. The general procedure has been to determine the load-elongation curves of fibers under various conditions. This procedure has been followed in the present work. The method employed is relatively simple and requires little equipment that is not generally available.

A sample of domestic wool was purified by successive extractions with alcohol and ether, followed by washing with water at about $40^{\circ}$ C. The fibers were for the most part nonmedullated and were fairly uniform in width along the 4-cm length used in this work, the average width as measured at 20 places being about 35 microns. Before measuring the fiber width, each end of the fiber was attached to a platinum-iridium hook, weighing about $0.35 \mathrm{~g}$, with asphalt (dissolved in chloroform) as the binding material. The measurements of the widths of the fibers were made in a room at $21^{\circ} \mathrm{C}$ and 65 -percent relative humidity), using a projection microscope equipped with a heat filter, and giving a magnification of about 700 diameters. Duplicate determinations of the effective diameter of the same fiber checked to within 1 percent. In addition to this method for the direct determination of fiber width, the fibers were calibrated by a reextension method, described later in this section.

The fibers were always soaked for 24 hours at $21^{\circ} \mathrm{C}$ in the solutions in which they were to be stretched. Loads were applied to the fibers 
and the extension was measured with the analytical balance and auxiliary equipment shown in figure 1. A fiber, $E$, of known length was attached to the left side of the balance beam, and the pointer of the balance was brought to the zero position by adding weights on the left-hand pan to counterbalance the rubber pad $G$. The lower hook on the fiber was then attached to the glass hook sealed to the bottom of the 250-ml Erlenmeyer flask $D$ resting on the movable platform $F .^{3}$ Flask $D$ contained enough of a given solution to assure complete immersion of the fiber during elongation. The load was applied by the addition of steel balls, each weighing $0.4392 \pm .0004 \mathrm{~g}$, to a spongerubber pad on the right-hand balance pan. The rubber pad contained small holes, each of which held one steel ball. The application of this stress causes an elongation of the fiber and a consequent leftward displacement of the pointer of the balance. By lowering platform $F$,

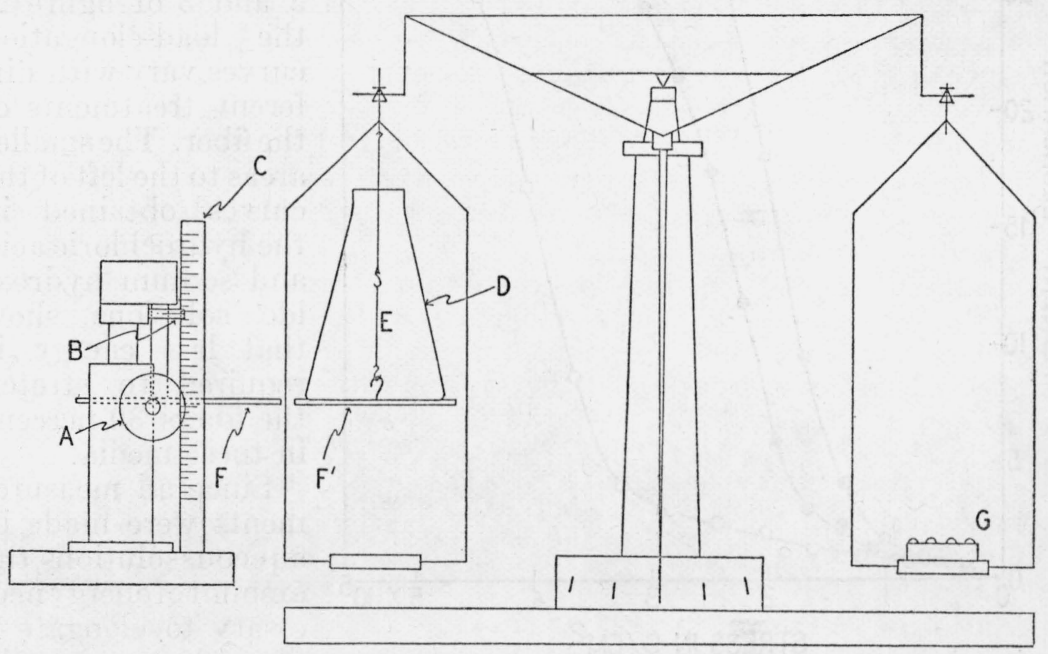

FIGURE 1.-Apparatus for determining the load-elongation curves of single wool fibers.

using thumbscrew $A$, the pointer was returned to the zero position, and the extent of vertical displacement was read on the scale $C$ by the index $B$. Elongation was read in this manner to $0.1 \mathrm{~mm}$. The balls were added at 30 -second intervals, and readings of elongation were made 15 seconds after the addition of each ball. The rate of applying stress for the fibers studied was approximately $1 \times 10^{5} \mathrm{~g} / \mathrm{cm}^{2} \mathrm{~min}$. The length at zero load was obtained by extrapolation, correcting for the weight of the lower hook. All load-elongation measurements were made at $21^{\circ} \mathrm{C}$.

The method described above has several advantages in addition to its simplicity. The regular lowering of the platform maintains the fiber in an effectively vertical position, which assures application of the full apparent stress. The platform may be allowed to remain in position long enough to make an unhurried reading of the scale. Although the loading process is a discontinuous one, which at first sight appears to be a disadvantage, the reproducibility of the measurements and the sensitivity of the method show this type of loading to be satisfactory for the determination of the load-elongation curves.

${ }^{3}$ During operation, platform $F$ is in position $F^{\prime}$. 
A typical load-elongation curve obtained with this apparatus for an untreated wool fiber in equilibrium with water at $21^{\circ} \mathrm{C}$ is shown in figure 2, curve 1. Speakman [7] has shown that such curves are most reproducible up to an elongation of 30 percent and that the area to the left of the curve, representing the amount of energy necessary to produce a given elongation, is a sensitive measure of changes

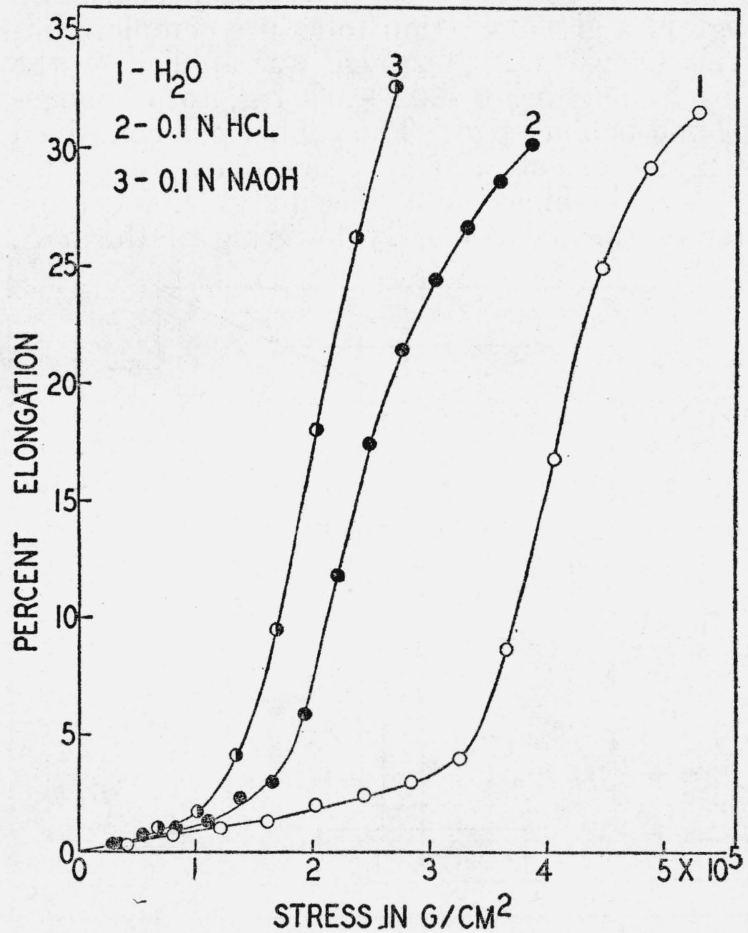

FIGURE 2.-Stress-strain load-elongation curves for wool fibers immersed in water, and in acid and alkaline solutions. in fiber extensibility. When the fibers are stretched beyond 30 percent, permanent alterations in their extensibility may occur.

As shown in curves 2 and 3 of figure 2, the load-elongation curves vary with different treatments of the fiber. The smaller areas to the left of the curves obtained in the hydrochloric acid and sodium hydroxide solutions show that less energy is required to stretch the fibers 30 percent in these media.

Since all measurements were made in aqueous solutions, the amount of energy necessary to elongate a fiber 30 percent in distilled water (approximately $\mathrm{pH} 5.8$ )

was taken as a standard. Comparison of the extensibilities of fibers in various solutions was facilitated by calculating the " 30 -percent index", which is defined as the ratio of the energy required to elongate a treated or untreated fiber 30 percent in a given medium to the energy which should be required to elongate the untreated fiber 30 percent in distilled water. Comparison of data by this method was limited to experiments in which the general shape of the curves was similar to that for an untreated fiber in distilled water.

It has been shown by Speakman [6] that fibers elongated 30 percent or less, after a 24-hour period of rest without load, will give load-elongation curves very nearly identical with the original curves. That the fibers used in this investigation possess this ability was demonstrated by reextending in distilled water, five individual fibers which 24 hours previously had been elongated 30 percent in distilled water. The mean value of their 30 percent indices was 0.996 . Wherever possible, the fibers used in the present work were first extended 30 percent in distilled water and then allowed to rest without load for 24 hours. They were then reextended or subjected to some treatment 
and reextended in a given medium. This procedure eliminated the necessity of measuring the cross-sectional area used to calculate the energies to a unit cross-sectional area. Fibers to be reextended by this method are referred to as "calibrated" fibers in this paper.

\section{RESULTS AND DISCUSSION}

\section{EFFECT OF TANNING}

Much has been written about tanning and there are many different views as to the nature of tanning processes. However, it is generally accepted that the principal effect of tanning is to decrease the swelling of proteins in aqueous media. In tanning collagen to prepare leather, it has been shown [8] that the acidcombining capacity is appreciably reduced. Tanning appears to affect wool similarly. Wool fibers were treated (refluxed) for 3 days at $50^{\circ} \mathrm{C}$ with a saturated solution of quinone in about $50 \%$ alcohol, after which they were washed for 24 $\mathrm{hr}$. in running distilled water. The quinone-tanned wool had an acidcombining capacity of 0.39 millimole $/ \mathrm{g}$, as compared to 0.80 millimole/g for the untreated fibers, which indicates that about half of the basic groups in wool reacted with the quinone.

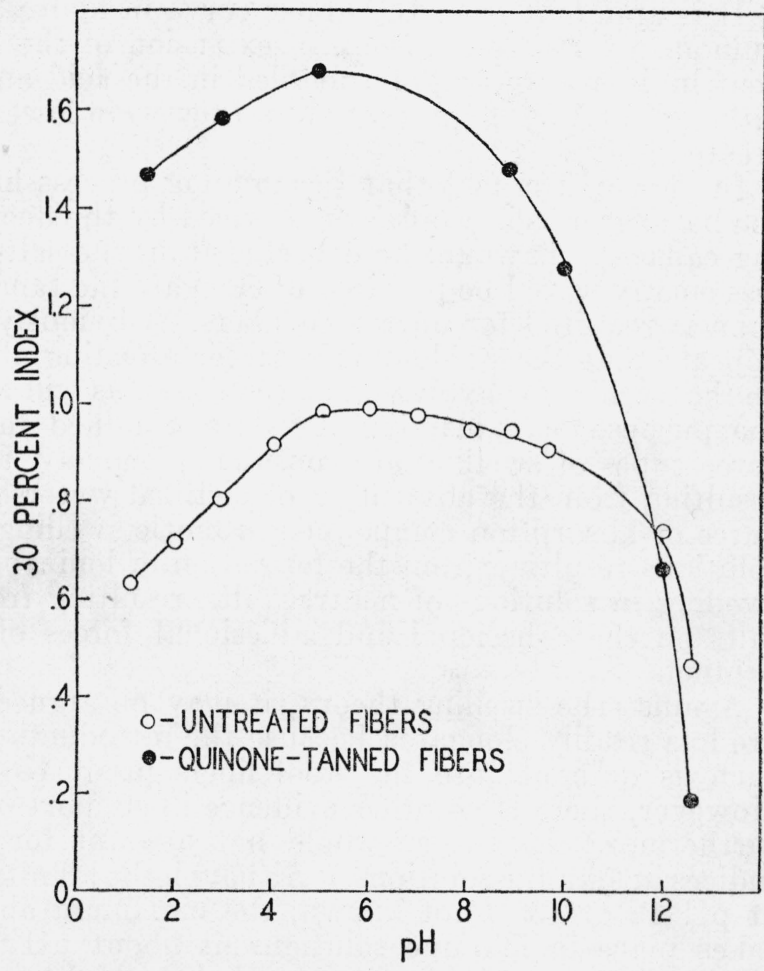

Determinations FIGURE 3.-Effect of tanning with quinone on the extensiof the 30-percent indices of untreated bilities of wool fibers in solutions of different $\mathrm{pH}$.

and quinone-tanned fibers in solutions having $\mathrm{pH}$ values ranging from about 1 to 12 are shown in figure 3 . The curve for the untreated wool is similar to that obtained by Speakman and Hirst, which exhibits a region of maximum stability between about $\mathrm{pH} 5$ and 7 , a region of linear decrease in the 30-percent indices from $\mathrm{pH} 5$ to 1 and a region above about $\mathrm{pH} 10$ in which the 30 -percent index decreases rapidly with increasing $\mathrm{pH}$. The maximum region is somewhat smaller than that obtained by Speakman and Hirst in unbuffered solutions but very similar to that obtained by them using acids and alkalies in $0.2 \mathrm{~N}$ solutions of sodium chloride. Buffer solutions, prepared according to 
Clark [9] were used in the present work, which probably accounts for the similarity of the shape of the curve obtained in the present work with that obtained in the presence of dilute solutions of sodium chloride.

The decrease in the 30-percent index of untreated wool in the acid solutions is practically reversible, since reextension of the fibers in distilled water after thorough washing yielded 30-percent indices of more than 0.98. Above $\mathrm{pH} \mathrm{8,} \mathrm{however,} \mathrm{the} \mathrm{degree} \mathrm{of} \mathrm{recovery} \mathrm{of} \mathrm{the}$ fibers decreases with increasing $\mathrm{pH}$. The 30 -percent index of fibers extended in $0.1 \mathrm{~N}$ sodium hydroxide, washed, and reextended in distilled water was only 0.59. This is in agreement with the known susceptibility of the fibers to chemical degradation in the morealkaline solutions.

It is apparent from the upper curve in figure 3 that tanning with quinone ${ }^{4}$ decreases the ease of extension of the fibers. The 30 -percent indices were roughly doubled in the acid and neutral solutions, although at very high pH values they were lower than those for untreated fibers.

In view of the fact that the tanning process has blocked many of the basic groups in wool (as evidenced by the decreased acid-combining capacity) it would be expected from the salt-linkage theory that less energy would be required to elongate the tanned fibers 30 percent than is required for untreated fibers. Obviously, this is not so. It appears that the predominant factor affecting the extensibility may be the swelling or hydration of the fibers, as will be shown later. For the purpose of explaining the data obtained in the present work, three types of swelling are considered; namely, imbibitional swelling resulting from the absorption of distilled water by wool to form solvates or absorption compounds; osmotic swelling, in acid or alkaline solutions resulting from the formation of ionizable protein salts; and swelling in solutions of neutral salts, resulting from the effect of the salts on the cohesional and adhesional forces of the water and the protein.

Against the swelling theory, it may be argued that tanned fibers are less readily elongated because the introduction of large molecules such as quinone into the wool fibers produces new cross linkages. However, there is no other evidence in support of such a theory and furthermore the theory would not account for the low 30-percent indices in alkaline solutions. Although the affinity of wool for quinone at $\mathrm{pH} 12$ or 13 is not known, the maximum absorption of quinone takes place in alkaline solutions at about $\mathrm{pH} 8$ to 11 [10], and it hardly seems probable that at slightly higher $\mathrm{pH}$ values the wool would lose all of its affinity for the quinone. A more probable mechanism for the behavior of the tanned fibers is that, in acid solution, less acid is bound by the tanned fibers than by untreated fibers and there is accordingly less osmotic swelling, whereas in alkaline solution, the carboxyl groups, which presumably are unaffected by the quinone are capable of binding as much alkali as untreated fibers. Thus the normal swelling would take place in alkaline solution in addition to the chemical degradation which is known to occur under these conditions.

- As indicated by alkali-solubility determinations, no significant amount of oxidation has occurred during treatment with quinone. 
It is interesting to note that the decrease in 30-percent index for the tanned fibers from $\mathrm{pH} 5$ to about $\mathrm{pH} 1$ is about half that for the untreated fibers between the same $\mathrm{pH}$ values. The fact that the tanned wool used for these experiments had only about one-half of the acid-combining capacity of the untreated wool is evidence that the extensibility of the fibers in this $\mathrm{pH}$ region is proportional to the amount of acid combined, as previously noted by Speakman and Stott [11]. This immediately suggests that at least two effects result from the tanning of wool with quinone; namely, the reaction of a portion of the basic groups with the quinone, which decreases the acid-combining capacity, thus decreasing the Donnan effect (osmotic swelling) in acid solutions, and the reaction of wool with quinone in a manner which decreases the swelling that occurs in water alone (imbibitional swelling), as indicated by the difference in 30-percent indices of the untreated and tanned fibers in the neutral region. This is also in keeping with the fact that wool takes up much more quinone than is accounted for by the basic groups.

\section{EFFECT OF DYEING WITH ACID DYES}

The dyeing of wool with a simple acid dye such as orange II appears to involve a less complicated mechanism than the tanning process. Although wool absorbs more quinone than can be accounted for by the basic groups, it has been shown by Smith and Harris [12] that it absorbs only 1 molecule of acid dye for each basic group when the dyeing is carried to equilibrium. The dyeing appears to be the result of the interaction of the acid groups of the dye molecules with the basic groups in wool, but the nature of the wool-dye compound is not known. If the dyeing results in the formation of highly ionized compounds, it would be expected that the extensibilities of the dyed fibers, for example at $\mathrm{pH} 1$, would be approximately the same as those of untreated fibers at the same pH. On the other hand, the formation of nonionized or weakly ionized compounds would appreciably change the extensibilities in acid solutions by decreasing that portion of the osmotic swelling caused by the acid. It seemed, therefore, that a study of the extensibilities of completely dyed fibers ${ }^{5}$ would offer some information as to the nature of the wool-acid dye complex in addition to further elucidating the factors which affect the extensibility of the fibers.

Single fibers were calibrated by the reextension method, then dyed for 20 hours at $50^{\circ} \mathrm{C}$ in a solution of Orange II in $0.1 \mathrm{~N}$ hydrochloric acid. (The stock-solution contained 5 millimoles of dye per liter and sufficient solution was used to assure an excess of dye. It has been shown [12] that under these conditions, wool absorbs about 0.8 millimole of dye per gram.) The fibers were washed in running distilled water for one hour and then allowed to remain in buffer solutions for 24 hours, after which they were reextended. The results given in table 1 show that the extensibilities of the completely dyed fibers in acid solutions are very similar to those of untreated fibers in distilled water. The basic groups not only appear to be blocked by the dye molecules, but they are at the same time rendered practically inactive.

\footnotetext{
${ }^{s}$ Fibers dyed under such conditions that all of the basic groups have reacted with dye molecules [12].
} 
TABLE 1.-Comparison between the 30-percent indices at different $\mathrm{pH}$ values of untreated wool fibers and fibers dyed to equilibrium with orange $I I$, when extended. in buffer solutions of different $\mathrm{pH}$ values

\begin{tabular}{|c|c|c|}
\hline \multirow{2}{*}{$\mathrm{pH}$} & \multicolumn{2}{|c|}{30 -percent index } \\
\cline { 2 - 3 } & Dyed fibers & $\begin{array}{c}\text { Untreated } \\
\text { fibers }\end{array}$ \\
\hline 1.42 & 1.01 & 0.66 \\
2.98 & 1.01 & .81 \\
4.95 & 0.99 & .98 \\
6.90 & .88 & .99 \\
\hline
\end{tabular}

In other words, when untreated wool is put in acid solutions, heteropolar compounds of wool and acid are formed, which facilitate extension of the fibers (by increasing osmotic swelling), whereas, when completely dyed, the wool and dye appear to form compounds which approach homopolar compounds in their behavior.

Unfortunately, the 30-percent indices of the dyed fibers could not be determined in alkaline solutions because of the reversal of the dyeing process. The somewhat low 30-percent index for the dyed fibers in solutions at $\mathrm{pH} 6.9$ indicates a shift in stability to the more acid region.

\section{EFFECT OF DEAMINATION ${ }^{6}$}

It would appear on first sight that the influence of the basic groups on the extensibility of wool could best be studied by comparing the properties of untreated and deaminated fibers. This would have the obvious advantage of eliminating the introduction into wool of new molecules, such as occurs in the tanning and dyeing processes. As will be shown later, however, the action of nitrous acid on wool is not limited to the amino groups, and as a result the value of this method of attack is somewhat questionable.

The deamination process has been frequently used by various investigators for the purpose of studying the role of the amino groups in wool. An investigation of the effect of nitrous acid on wool revealed two principal weaknesses in this method, namely, that it is impossible to completely deaminate wool in a reasonable length of time, and that the state of the sulfur of the cystine in wool is altered during deamination.

It has been shown $[13,14]$ that deaminated proteins retain a considerable portion of their acid-combining capacities, even after prolonged treatment with nitrous acid. Experimental results indicate that there is a sudden drop in acid-combining capacity after a very short treatment with nitrous acid, followed by a very slow decrease in the acid-combining capacities during the continued treatment. This is in agreement with the results of Rutherford, Harris, and Smith [15], who studied the rates of evolution of nitrogen from various proteins during treatment with nitrous acid and found that there is a primary reaction with a rapid rate of evolution of nitrogen, followed by a secondary reaction with a very much slower evolution of nitrogen.

\footnotetext{
${ }^{6}$ In the present paper, deamination refers only to removal of amino groups with nitrous acid and has no quantitative significance as to the extent or completeness or their removal.
} 
The effect of the deamination process on the state of the sulfur in wool practically precludes the making of rigorous comparisons between the untreated and deaminated fibers. Harris and Smith [16] have recently shown that during treatment with oxidizing agents, the disulfide sulfur appears to be changed to higher states of oxidation, the existence of oxidation derivatives being indicated by four different methods. Nitrous acid is an active oxidizing agent and, as such, should also be capable of at least partial oxidation of the sulfur in wool. That oxidation does occur during deamination is indicated by three ${ }^{7}$ of the methods used by Harris and Smith. The deaminated wool gave a negative lead acetate test, ${ }^{8}$ and showed increasing alkali-solubilities and decreasing cystine contents with increasing time of deamination.

In view of these apparent difficulties, it was necessary to reinvestigate the extensibility of deaminated fibers from the standpoint of the different reactions which may occur during deamination. Wool fibers were treated for different lengths of time at $20^{\circ} \mathrm{C}$ with a solution of nitrous acid (one volume of glacial acetic acid to four volumes of a solution containing $30 \mathrm{~g}$ of sodium nitrite in $100 \mathrm{ml}$ of water), the ratio of solution to wool being approximately 500 to 1 . The fibers were thoroughly washed in running distilled water and their 30-percent indices in solutions of different $\mathrm{pH}$ values determined. The results are recorded in table 2.

From the foregoing discussion on the reactions of wool with nitrous acid, at least two effects of the deamination process on the extensibility of wool fibers may be expected, namely, an increase in 30-percent index in acid solutions caused by a reduction in osmotic swelling resulting from loss of amino groups and corresponding acid-binding capacity, and a decrease in 30-percent index caused by oxidation of the disulfide groups and the subsequent weakening of the bonds between the disulfide sulfur atoms. The latter effect should increase with increasing $\mathrm{pH}$, since it has been shown by Lavine [17] and Toennies [18] that the stability of the intermediate oxidation derivatives of cystine decreases with increasing $\mathrm{pH}$.

TABLE 2.-The 30-percent indices of wool fibers which have been deaminated for different lengths of time with nitrous acid

\begin{tabular}{|c|c|c|c|c|}
\hline & \multicolumn{3}{|c|}{ 30-percent indices } \\
\hline $\begin{array}{c}\text { Duration of } \\
\text { treatment } \\
\text { with } \mathrm{HNO}_{2}\end{array}$ & $\mathrm{pH} 1.1$ & $\mathrm{pH} 4.0$ & $\mathrm{pH} 7.0$ & $\mathrm{pH} 12.0$ \\
\cline { 2 - 5 } & & & & \\
\hline Hours & & & & \\
0 & 0.66 & 0.93 & 0.98 & 0.76 \\
3 & .72 & .85 & .75 & .48 \\
24 & .73 & .85 & .73 & .39 \\
48 & .74 & .84 & .68 & .29 \\
96 & .74 & .84 & .64 & .28 \\
192 & .72 & .80 & .62 & .21 \\
\hline
\end{tabular}

An examination of the data in table 2 shows that the results of these experiments are in agreement with the above-mentioned postulates. The 30-percent indices of all of the deaminated fibers are

\footnotetext{
7 The fourth method, namely, reduction with hydrochloric acid-potassium iodide solutions, could not be used because of interference from what appeared to be nitroso derivaties formed during deamination.

8 Samples of wool were prepared for this test by deamination at 0 to $5^{\circ} \mathrm{C}$ to prevent excessive yellowing of the wool.
} 
greater at $\mathrm{pH} 1.1$ than are those of the untreated fibers. At this $\mathrm{pH}$, the inhibition of osmotic swelling resulting from loss of amino groups (the acid-combining capacity of the deaminated fibers is roughly half of that for untreated fibers) is the predominant factor, the partially oxidized disulfide groups being moderately stable at this $\mathrm{pH}$. At pH 4 the 30-percent indices are slightly lower than for the untreated fibers. Since the number of basic groups in the deaminated. wool is far greater than the number of moles of acid bound by wool at $\mathrm{pH} 4$, it is to be expected that there should be very little difference between the osmotic swelling of the treated and untreated fibers. However, at this $\mathrm{pH}$ the instability of the oxidized sulfur groups becomes appreciable [17], thus accounting for the lowering of the 30-percent indices of the deaminated fibers. At the higher $\mathrm{pH}$ values, the differences become even more pronounced since the instability of the oxidized sulfur groups increases rapidly in alkaline solutions. The effects of the prolonged treatments with nitrous acid are especially noticeable at $\mathrm{pH} 7$ and above. Fibers deaminated for 48 hours or longer and stretched in solutions at pH 12 no longer gave load-elongation curves similar to those for untreated fibers.

According to Speakman and Stott [13], "the resistance of wool fibers to extension is less in acid solution than in water, owing to the rupture of salt linkages between peptide chains. Similarly, deaminated fibers are less resistant to extension in water than untreated fibers, the reduction in the resistance to extension being dependent on the extent of deamination.- A critical test for complete deamination is to be found in the fact that completely deaminated fibers should be no more difficult to stretch in water than in hydrochloric acid solution at $\mathrm{pH}$ 1." [Italics ours.] In addition, Speakman and Stott presented data which presumably indicated that the load-extension curve of completely deaminated fibers in distilled water and at $\mathrm{pH} 1$ are almost identical.

The results of the present investigation show that the extensibilities of deaminated fibers cannot be used as a measure of the completeness of deamination. Deaminated fibers were found to be more resistant to extension in a solution of $\mathrm{pH} 1.1$ than untreated fibers in spite of the apparent attack on the sulphur groups, which indicates that the main effect at this $\mathrm{pH}$ is the lowering of the osmotic swelling by reducing the amount of acid bound by the wool. The ease of extension of the deaminated fibers in neutral solution ( $\mathrm{pH}$ 7.0) increases relatively rapidly with increasing duration of deamination, whereas at $\mathrm{pH} 1.1$ the fibers at first become slightly more difficult and then slightly easier to stretch. In other words, the extensibilities of deaminated fibers in solutions of $\mathrm{pH} 1$ and $\mathrm{pH} 7$ are not the same nor are the changes which are produced in the ease of extension in the two solutions, the result of the same reaction. It follows then that complete deamination cannot be defined in terms of the extensibility of wool. It appears that Speakman and Stott's [13] conclusion that wool fibers may be "completely deaminated" by 50 hours' treatment with the Van Slyke reagent was the result of a coincidence in which. they obtained practically identical load-elongation curves for a deaminated fiber in distilled water and at pH 1 . As was previously pointed out, the 30-percent indices for deaminated fibers at pH 1.1 are almost constant, while those obtained at $\mathrm{pH} 7$ decrease with increasing duration of treatment with nitrous acid. It should be noted that extend- 
ing strongly deaminated fibers more than once is a questionable procedure and as a result at least three fibers, previously calibrated and then deaminated, were used for each determination shown in table 2.

\section{EFFECT OF NEUTRAL SALTS}

In addition to the effect produced by acids and alkalies, neutral salts also may have a marked influence on the swelling of wool. Actually, there are salts which depress swelling as well as salts which increase it, the former producing what is commonly known as "salting out" and the latter, "salting in" or "peptization". The relative effect of various salts was first investigated by Hofmeister [19], who arranged the salts in an order corresponding to their effect on the proteins.

Whereas an insoluble protein such as wool may swell in distilled water by an imbibition process and in acids or alkalies by osmotic forces resulting from salt formation, the mechanism by which salts influence the swelling has not been satisfactorily explained. It appears, as suggested by Gibson and Kincaid [20] that the salts influence the structure of water by strengthening or weakening the electrostatic bonds which hold the molecules of water together. There is also the possibility that the salts influence the forces of cohesion in the protein. It would be expected, then, that when the cohesional forces between the water molecules become relatively greater than the adhesional forces between the protein and water, depression of swelling ("salting-out") will take place. Similarly, when the adhesional forces between water and protein are relatively greater, increased swelling ("salting-in") will result.

Since the $\mathrm{pH}$ of solutions of most of the neutral salts lies within the pH stability range for wool, and since the free amino and carboxyl groups should not be attacked by the salts, the investigation of the effect of various neutral salts offered another approach to the study of the nature of the forces involved in the extension of the fibers. Accordingly, calibrated fibers were soaked for 24 hours in $1 \mathrm{~N}$ solutions of various potassium salts and then extended in the same solutions. When the data were arranged in order of decreasing 30-percent indices, as shown in table 3 , it was found that the anions of the salts were arranged in an order corresponding to their ability to increase the swelling of proteins [19].

TABLE 3.-Effect of normal solutions of various potassium salts on the extensibility of wool fibers

\begin{tabular}{|c|c|}
\hline Solution & $\begin{array}{l}\text { 30-percent } \\
\text { index }\end{array}$ \\
\hline $\begin{array}{l}1 \mathrm{~N} \mathrm{~K} \mathrm{SO}_{4} \\
1 \mathrm{~K} \mathrm{KOOCCH}_{3} \\
1 N \mathrm{KCl} \\
1 \mathrm{KBr} \\
1 \mathrm{KI} \\
1 N \mathrm{KCNS}\end{array}$ & $\begin{array}{r}1.03 \\
1.02 \\
1.01 \\
0.97 \\
.90 \\
.83\end{array}$ \\
\hline
\end{tabular}

That the salts influenced the swelling of the wool fibers was corroborated by measuring the change in the diameters of fibers immersed in $1 N$ solutions of potassium bromide and potassium thiocyanate. 
The method employed was similar to that described by Speakman and Stott [11] and consisted essentially in the mounting of 5 fibers on a glass slide marked with 10 lines, $1 \mathrm{~mm}$ apart so that the fibers and lines crossed each other at right angles. The ends of the fibers were sealed to the glass with asphalt so that the slide and fibers could be immersed in any liquid under consideration. The fiber widths were determined microscopically on both sides of the intersections of the fibers and the lines, so that 100 measurements were made on each slide. All the experiments were conducted in a room kept at $21^{\circ} \mathrm{C}$. The widths were first determined after soaking in distilled water for 24 hours and after 24 hours in the desired reagent. By this method, it was found that the average widths of the wool fiber increased 0.2 percent in $1 \mathrm{~N}$ potassium bromide, and 1.0 percent in $1 \mathrm{~N}$ potassium thiocyanate solutions over what they were in distilled water.

Speakman and Hirst [2] investigated the stretching of wool in 0.2 $N$ solutions of sodium chloride containing varying amounts of hydrochloric acid, with the idea of studying the action of acids on wool in the absence of swelling. From their results they concluded that "the fact that swelling can be reduced without interfering with the action of acid in facilitating fiber-extension, is a confirmation of the view that swelling is not the primary cause of a reduced resistance to extension." However, actual measurements of fiber diameters indicate that in $0.1 \mathrm{~N}$ hydrochloric acid solutions the amount of sodium chloride they used reduces the swelling obtained with acid alone by only about 25 percent. If, however, a $0.1 N$ solution of hydrochloric acid saturated with sodium chloride is used, not only does the osmotic swelling produced by the acid appear to be eliminated but there also appears to be a contraction in fiber width. Consistent with this is the fact that wool fibers are more difficult to elongate in such a solution than in water, the 30-percent index for the fibers being 1.10 . The acid-combining capacity of wool in a $0.1 \mathrm{~N}$ solution of hydrochloric acid, saturated with sodium chloride is $1.12^{9}$ millimoles of acid per gram of wool, which indicates that any existing salt linkages would have been broken and on the basis of the salt-linkage theory, the fiber should have been easier to stretch.

\section{RELATION OF SWELLING TO THE EXTENSIBILITY OF WOOL}

Although it has been shown that the extensibility of a fiber is qualitatively influenced by the factors which affect the swelling of the wool, it is not to be expected that the ease of elongation will be directly proportional to the degree of swelling. That there is a relationship for a specific type of swelling is shown in table 3 and in figure 4. The data for the latter are those of Speakman $[2,11]$ and his collaborators. The curve indicates a relationship between the ease of elongation and the osmotic swelling. However, when the effects of osmotic swelling and swelling produced by a "salting-in" salt on the extensibilities of the fibers are compared, somewhat different results are obtained. The 30-percent indices of fibers stretched in a hydrochloric acid solution of $\mathrm{pH} 2.9$ and in a $5 \mathrm{~N}$ solution of

\footnotetext{
9 This is not strictly comparable to the value of 0.80 obtained for $0.1 \mathrm{NHCl}$ alone, in which no correction is made for swelling. Reduction of swelling by the $\mathrm{NaCl}$ gives a higher apparent value for the acid-combining capacity. In addition, the hydrogen ion activity of the solutions is greatly changed by the NaCl [21].
} 
lithium bromide are 0.81 and 0.82 , respectively. The average increase in the fiber diameter in the acid solution as compared to water was 1.8 percent and in the lithium bromide solution, 3.1 percent. A possible explanation for such differences may be found in a consideration of the electrovalent linkages in the wool molecule. As was previously pointed out, the fiber appears to consist of long-chain polypeptides held together by a variety of cross linkages of the covalent and electrovalent types. The valence forces vary according to the type of linkage. The electrovalent forces, however, are of essentially two types; Coulomb forces which vary inversely as the

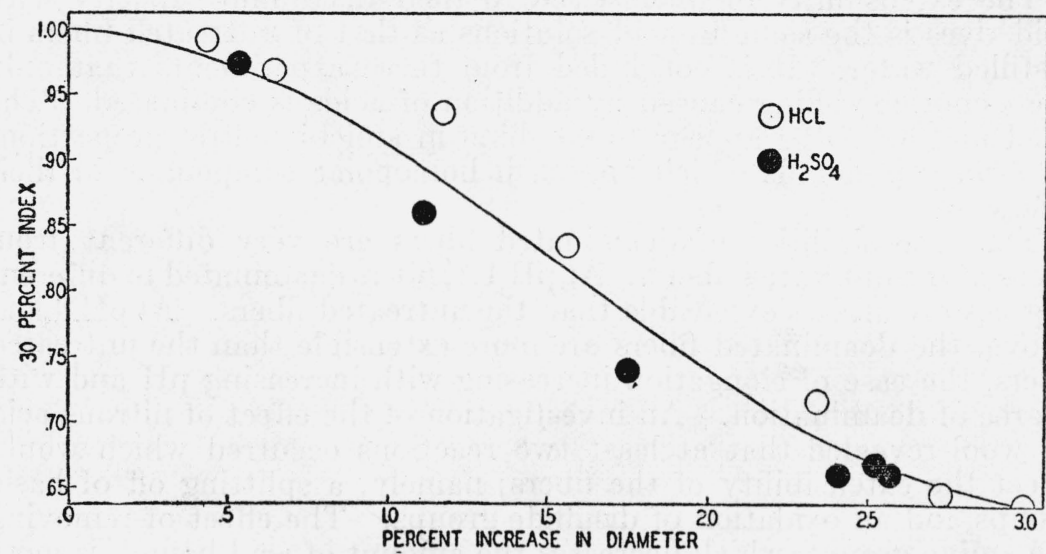

Figure 4.-Relation between extensibility and swelling of wool fibers in acid solutions of different concentrations.

Data from Speakman $[2,11]$

square of the distance and Van der Waal's forces which vary inversely as the sixth and higher powers of the distance. It is obvious, then, that the extensibility of the fiber should depend on the relative proportions of the various types of forces which are affected in the different types of swelling. In other words, a given amount of swelling which involves a relatively high proportion of Coulomb forces should produce a less extensible fiber than a similar amount of swelling invo ${ }^{\mathrm{I}}$ ving a higher proportion of Van der Waal's forces.

\section{SUMMARY}

The results of this investigation indicate that salt linkages of the type which might be formed by an attraction between the free amino and carboxyl groups in wool do not appreciably contribute to the physical stability of the fiber in aqueous solutions. It appears that the extensibility of wool fibers in aqueous solutions is governed, for the most part, by factors which influence the swelling or hydration of the wool. For the purpose of explaining the data obtained in the present work, three types of swelling are considered, namely, imbibitional swelling resulting from the absorption of distilled water by wool to form solvates or adsorption compounds; osmotic swelling, in acid or alkaline solutions resulting from the formation of ionizable protein salts; and swelling in solutions of neutral salts, resulting from 
the effect of the salts on the cohesional and adhesional forces of the water and the protein.

Tanning with quinone appears to decrease the ease of extension of the fibers (except in strongly alkaline solutions) by decreasing the swelling of the wool. The experimental data suggest that part of the effect results from blocking some of the basic groups and reducing some of the osmotic swelling, while the remainder of the effect is caused by a decrease in imbibitional swelling. The results are consistent with the fact that proteins take up more tanning materials than can be accounted for by the basic groups.

The extensibility of fibers dyed to their maximum capacity with acid dyes is the same in acid solutions as that of untreated fibers in distilled water. It is concluded from these experiments that only the osmotic swelling caused by addition of acids is eliminated. The wool and acid dye appear to combine in stoichiometric proportions to form compounds which approach homopolar compounds in their behavior.

The extensibilities of deaminated fibers are very different from those of the untreated fibers. At $\mathrm{pH}$ 1.1, fibers deaminated to different degrees are all less extensible than the untreated fibers. At pH 4 and above, the deaminated fibers are more extensible than the untreated fibers, the ease of elongation increasing with increasing $\mathrm{pH}$ and with degree of deamination. An investigation of the effect of nitrous acid on wool revealed that at least two reactions occurred which would affect the extensibility of the fibers; namely, a splitting off of basic groups and an oxidation of disulfide groups. The effect of removing the amino groups, which decreases the amount of acid bound, is most pronounced when the fibers are extended in the strongly acid solutions. The osmotic swelling is decreased and this results in a decreased extensibility. This effect becomes less pronounced as the $\mathrm{pH}$ of the solutions with which the wool is in contact increases. On the other hand, the effect on the sulfur is at a minimum in the more acid solutions but becomes more pronounced as the $\mathrm{pH}$ increases. The net effect then, is a combination of the two reactions.

Neutral salts increase the ease of elongation of the fibers in an order corresponding to their abilities to increase the swelling of proteins. $0.2 N$ solutions of sodium chloride cause only a relatively small decrease in the osmotic swelling produced by hydrochloric acid. However, saturated solutions of this salt not only appear to eliminate the osmotic swelling produced by $0.1 \mathrm{~N}$ hydrochloric acid but also actually produce a contraction in the fiber. In spite of the fact that in such a system the wool takes up more acid than wool in acid solutions without sodium chloride, the fibers in contact with the acid-salt solution are more difficult to stretch than untreated fibers in water alone.

Although the extensibility of the fiber is modified by the factors which affect the swelling of wool, it is not necessarily directly proportional to the degree of swelling. In general, it appears to depend on the relative proportion of the different electrovalent cross linkages which are affected in each type of swelling. 


\section{REFERENCES}

[1] J. Textile Inst. 27, p281 (1936).

[2] Trans. Faraday Soc. 29, 148 (1933).

[3] Proc. Roy. Soc. A. 94, 460 (1918).

[4] Z. tech. Physik 6, 124 (1925).

[5] J. Textile Inst. 15, T207 (1924).

[6] Phil. Trans. Roy Soc. London A. 232, 333 (1933).

[7] J. Textile Inst. 17, T457 (1926); 18, T431 (1927); Proc. Roy. Soc. B103, 377 (1928).

[8] Ind. Eng. Chem. 18, 84 (1926).

[9] The Determination of Hydrogen Ions (Williams and Wilkins Co., p. 75, 1920).

[10] Ind. Eng. Chem. 16, 925 (1924).

[11] Trans. Faraday Soc. 30, 539 (1934).

[12] J. Research NBS 19, 81 (1937) RP1012.

[13] J. Soc. Dyers Colourists 50, 341 (1934).

[14] J. Gen. Physiol. 6, 94 (1923-24)

[15] J. Research NBS 19, 467 (1937) RP1038.

[16] J. Research NBS 18, 623 (1937) RP998.

[17] J. Biol. Chem. 113, 583 (1936).

[18] Personal communication.

[19] Arch. expt. Path. 25, 13 (1888); 28, 219 (1891).

[20] J. Am. Chem. Soc. 59, 579 (1937).

- [21] J. Research NBS 14, 217 (1935) RP'765.

Washington, September 24, 1937. 